\title{
$\begin{array}{ll}\text { Research Square } & \begin{array}{l}\text { Preprints are preliminary reports that have not undergone peer review. } \\ \text { They should not be considered conclusive, used to inform clinical practice, } \\ \text { or referenced by the media as validated information. }\end{array}\end{array}$ \\ Evidence of Epstein-Barr Virus Infection Association With Gastric Cancer and Gastroduodenal Diseases
}

\section{Arghavan Zebardast}

Babol University of Medical Sciences

\section{Maryam Pazhoohan}

Babol University of Medical Sciences

\section{Azadeh Yazdani Cherati}

Babol University of Medical Sciences

\section{Saghar Saber Amoli}

Department of Microbiology, School of Medicine, Babol University of Medical Sciences, Babol, Iran

\section{Yousef Yahyapour}

Infectious Diseases \& Tropical Medicine Research Center, Health Research Institute, Babol University of Medical

Sciences, Babol, Iran

\section{Mohammad Ranaee}

Department of Pathology, School of Medicine, Babol University of Medical Sciences, Babol, Iran

\section{Javad Shokri Shirvani}

Department of Internal Medicine, Faculty of Medicine, Babol University of Medical Sciences, Babol, Iran

Farzin Sadeghi ( $\nabla$ sadeghifarzin6@gmail.com )

Cancer Research Center, Health Research Institute, Babol University of Medical Sciences, Babol, Iran

\section{Research Article}

Keywords: Epstein-Barr virus, gastric cancer, gastroduodenal disease, Helicobacter pylori

Posted Date: October 6th, 2021

DOl: https://doi.org/10.21203/rs.3.rs-740778/v1

License: (c) (i) This work is licensed under a Creative Commons Attribution 4.0 International License. Read Full License 


\section{Abstract}

Background: Epstein-Barr virus (EBV) is detected in epithelial tumors, such as nasopharyngeal carcinoma and gastric cancer (GC). EBV-associated gastric cancer is a distinct molecular subtype of gastrointestinal carcinomas as defined by Cancer Genome Atlas. This gamma-Herpes virus is present in approximately $10 \%$ of gastric carcinomas.

Methods: The present study aimed to investigate the presence of EBV genome in gastric cancer and other gastroduodenal diseases either alone or together with Helicobacter pylori (HP). We examined 237 samples from Iranian patients diagnosed with GC and gastroduodenal disease for EBV infection by quantitative Real-Time PCR.

Results: Of the 237 samples tested, EBV DNA was detected in 37 samples (15.6\%), in 13 of the 81 GC cases (16\%), and 24 of the 156 non-cancerous samples (15.4\%). All samples containing EBV were gastric cancer of the intestinal type. Of 37 EBV-positive samples, 20 (54.1\%) were over 55 years old and 20 (54.1\%) were male. The EBV-EBER (EBV-encoded small RNA) DNA copy number in the gastric cancer group (mean $=2.14 \times 10^{-1}$ copies $/$ cell) was higher than that in the gastroduodenal disease group (mean $=1.39 \times 10^{-2}$ copies $/$ cell), and this difference was statistically significant $(P>$ 0.001). Moreover, the concurrent infections with EBV and HP were detected in 17 out of 35 EBER-positive samples (48.6\%), 6 (17/1\%) cases were in the gastric cancer group and $11(31 / 4 \%)$ cases were in the gastroduodenal disease group.

Conclusions: In the present study, a high incidence (16\%) of EBVaGC was observed in Babol city, Northern Iran. Also, the higher number of copies of EBV EBER DNA in the GC group than in the non-cancer group confirmed the possible role of EBV in inducing cancer. EBVaGC is not endemic in any region and varies in different nations. Therefore, further studies are needed to determine the role of this virus in the development of GC and other gastroduodenal diseases.

\section{Introduction}

Gastric cancer (GC) is the world's fifth most prevalent cancer and the third major cause of cancer mortality (1). The etiology of GC involves interactions of many risk factors, including environmental, genetic, lifestyle, and infectious factors (2). Helicobacter pylori infection (HP) has been identified as the most important risk factor in the infectious etiology of GC and other gastroduodenal disorders $(3,4)$. Infection with Helicobacter pylori causes an inflammatory response that results in non-neoplastic lesions such as gastritis (GA), gastric ulcer (GU), and duodenal ulcer (DU). In a small group of subjects, atrophy and loss of gastric glands develop, followed by the aforementioned inflammatory lesions, which may eventually develop into neoplastic transformation (5).

Epstein-Barr virus (EBV), a common oncogenic virus, is found in roughly $10 \%$ of gastric carcinomas (6). Epstein-Barr virus persistently infects about $95 \%$ of the world population, usually residing in memory B cells in a latent state (7). Intermittent episodes of viral reactivation are thought to occur in infected memory B cells that circulate in the gastrointestinal tract and produce viral particles that may promote infection of gastric epithelial cells $(8,9)$. Although viral reactivation triggers a local inflammatory response, much like HP infection is crucial to the carcinogenic process, the relative role of EBV in early inflammatory gastroduodenal lesions remains unclear.

Quantitation of viral genome copy numbers in blood and other body fluids is an important clinical indicator of viral disease. Viral titer in plasma and peripheral blood has been confirmed as a valuable prognostic criterion for EBVassociated tumors, such as nasopharyngeal carcinoma and hematologic malignancies (10-12). However, viral load in EBV-associated tumor tissue has not been extensively studied. The study by Ryan et al. found that gastric tissue in which EBV infects epithelial cells has a nearly 3000-fold higher viral load than tissue with only infected B cells (13). According to the aforementioned study, a cutoff value of 2000 EBV genome copies per $10^{5}$ cells is a valuable threshold to distinguish EBV infection of gastric epithelial cells from gastric tissues with only infected B cells (13). A recent study 
provided data supporting a role for EBV in GC and early precursor lesions including non-atrophic GA (9). However, the exact EBV copy number per cell count has not yet been studied in other gastroduodenal lesions at risk for malignant transformation, including GA, GU, and DU.

Hence, the facts reviewed above encouraged us to investigate whether EBV could have any association with the pathogenesis of gastric cancer and other gastroduodenal diseases either alone or together with HP. In this study, we tested 237 fresh or formalin-fixed paraffin-embedded (FFPE) samples of Iranian patients diagnosed with gastric cancer and gastroduodenal diseases (GA, GU, DU) as well as gastric congested mucosa (CM) from healthy subjects for the presence of EBV sequences in terms of viral genome copy number per cell.

\section{Methods}

\section{Clinical Samples}

The current cross-sectional study included 237 gastroduodenal tissue samples from the Ayatollah Rouhani Hospital's Pathology Department, which is associated with Babol University of Medical Sciences. A total of 129 gastroduodenal fresh biopsy specimens, including 52 GA, 20 GU, 31 DU, and 26 GC were obtained by gastroenterologists from individuals who had upper gastro-duodenal endoscopy. and one hundred and eight FFPE resection specimens including $55 \mathrm{GC}$ and $53 \mathrm{CM}$ from healthy subjects were collected. Demographic characteristics of samples were obtained from the clinical records of the patients in the hospital. HP infection in all biopsy specimens was determined by a rapid urease test (RUT) as part of a regular procedure in two of the above hospitals. The ethics committee of Babol University of Medical Sciences approved this study, and all subjects gave written informed consent. Also, all methods were performed in accordance with the relevant guidelines and regulations.

\section{DNA Extraction}

Formalin-fixed paraffin-embedded resection specimens deparaffinized according to a previously described procedure $(14,15)$. The tissue genomic DNA Extraction Mini Kit (Favorgen Biotech Corp., Taiwan) was used to extract DNA from 25 $\mathrm{mg}$ of fresh and FFPE samples according to the manufacturer's instructions. Briefly, for tissue dissociation $200 \mu \mathrm{L}$ of FATG1 tissue lysis buffer and $20 \mu \mathrm{L}$ of proteinase $\mathrm{K}(10 \mathrm{mg} / \mathrm{mL})$ were added to each tissue containing a microcentrifuge tube. Samples were subsequently incubated at $60^{\circ} \mathrm{C}$ until the tissue was lysed completely. DNA cleanup was done by mini spin column (silica matrix) according to the manufacturer's instructions. As an extraction negative control, tissue samples were treated concurrently with sterile microcentrifuge tubes containing only reaction mixtures. A NanoDrop spectrophotometer was used to evaluate the quality and amount of isolated DNA (Thermo Scientific, Wilmington, USA). Fresh tissue samples had an isolated DNA yield of 100-400 ng/L, whereas FFPE tissue samples had an isolated DNA yield of 30-70 ng/L. Eluted DNA from fresh and FFPE tissue samples had an A260/A280 ratio of 1.7, indicating that the genomic DNA was of excellent quality.

\section{EBV Quantitative Real-Time Polymerase chain reaction}

To detect and measure the amount of EBV viral load, using a Rotor-Gene Q Real-Time PCR system (QIAGEN GmbH, Hilden, Germany), quantitative Real-Time PCR was carried out through the primer sets and a TaqMan probe specific for the EBV EBER (EBV-encoded small RNA) gene according to a previously described procedure (16). As previously stated, viral copies were normalized to the amount of cell equivalents by measuring a single copy cellular RNase P gene (17). Negative results for human RNase $P$ gene amplification were regarded as having insufficient DNA integrity, and samples were re-extracted until RNase P amplification was obtained. Gene synthesis service constructed plasmids with cloned EBV EBER and human RNase P gene target sequences (quantitative standards for Real-Time PCR, Shanghai Generay Biotech Co., Ltd). A total of 100 ng of purified DNA was used in each Real-Time PCR reaction. A standard curve was 
created utilizing a tenfold dilution series of the EBV EBER plasmid in genomic extracts from EBV negative fresh and FFPE samples to test the sensitivity of quantitative Real-Time PCR. As a negative control, reaction mixtures without a DNA template were used, and DNA extracted from the supernatant of an EBV-producing B-cell line (B95-8) was used as a positive control.

\section{Statistical Analysis}

Data were analyzed using R 3.4.1, "arm", and "ggplot2" packages. The Shapiro-Wilk test was used to determine if the variables had a normal distribution. Descriptive results were presented as mean \pm standard deviation for normal quantitative variables and number (percent) for count data. Median and interquartile range (IQR) was used for the nonparametric variable which did not have a normal distribution. The independent sample t-test or Kruskal-Wallis test was used for comparing the mean or distribution of quantitative variables as appropriate. The Chi-square test was used for assessing the association of qualitative variables. Statistical significance was described as a P-value of less than 0.05 .

\section{Results}

Patient's characteristics

In this investigation, out of the 237 enrolled subjects (mean age $53.3 \pm 16.7$ years, range 15-90 years), 81 (34.2\%) had GC, 51 (21.5\%) had GA, 20 (8.4\%) had GU, and 32 (13.5\%) had DU; 53 samples (22.4\%) were CM of healthy subjects. Out of 237 patients, 130 (54.9\%) cases were from men and 107(45.1\%) were from women. All cancerous samples were primary adenocarcinoma. Cancerous samples were divided into two groups: 69 (85.2\%) with gastric adenocarcinoma, intestinal type, and 11 (13.6\%) with gastric adenocarcinoma, diffuse type. The type of gastric adenocarcinoma was unknown in 1 sample. The demographic, clinical and pathological characteristics of 237 patients included in this investigation are summarized in Table 1. According to the results, there was a significant relationship between age, gender and pathological diagnosis ( $P>0.001$ and $P=0.013$, respectively). The majority of $\mathrm{GC}$ specimens belonged to men $(57 / 81,70.4 \%)$. Also, the majority of patients with GC $(75.3 \%)$ and GU (65\%) were older than 55 years, while those with GA, DU, and CM, were less than 55 years.

Helicobacter pylori infection was detected in $90.3 \%$ of DU, $39.5 \%$ of GC, $35.0 \%$ of GU, and $22.4 \%$ of GA subjects. While none of the CM specimens from healthy subjects was HP positive. As shown in Table 1, there was a substantial difference in the prevalence of HP infection among pathology groups $(P>0.001)$. In contrast, no significant relationship between family history of gastric cancer, smoking, alcohol drinking, or drug use and pathologic diagnosis was observed. In addition, the mean body mass index (BMI) of the participants in the research was $25.5 \pm 4.6$ (range 16.3-50.1). There was a significant difference between different BMI groups $(P=0.002)$ and pathology diagnosis and most people with $G C$ were in the range of lean and normal weight (66/7\%) (Table 1).

\subsection{Detection and Quantitation of EBV}

Of the 237 studied samples, the EBER gene was detected in 37 specimens (15.6\%). The EBV infection rate was found higher in patients with GU (35\%) and DU (21.9\%) than in patients with GC (16\%) and GA (19.6\%) (Table 1). Epstein-Barr virus EBER gene was not detected in any of the $\mathrm{CM}$ samples. The presence of the EBER gene was significantly related to the pathologic diagnosis $(P=0.002)$. All specimens containing EBV were intestinal-type gastric cancer, and none of the diffuse-type samples were infected with EBV. There was no significant difference between EBER gene frequency in paraffin cancer samples $(16.4 \%)$ and fresh cancer samples $(15.4 \%)(P=0.911)$.

To determine the EBV EBER DNA load by Real time PCR method, 37 EBER positive samples were classified into gastric cancer and gastroduodenal disease groups. The EBV EBER DNA load was determined as the viral copy number per cell 
using a proven single-copy gene, human RNase P. The existence of adequate amplifiable DNA could be indicated by the amplification of this cellular gene. Human RNase $P$ gene was detected in the extracted DNA from all specimens. The EBV EBER DNA copy number in the gastric cancer group (mean $=2.14 \times 10^{-1}$ with range of $2.14 \times 10^{-2}$ to

$4.10 \times 10^{-1}$ copies/cell) was higher than gastroduodenal diseases group (mean $=1.39 \times 10^{-2}$ with range $1.11 \times 10^{-3}$ to $2.35 \times 10^{-2}$ copies/cell), and this difference was statistically significant $(P>0.001)$ (Fig. 1). Table 2 summarizes the demographic, clinical and virologic parameters of 37 EBER-positive patients with GC and gastroduodenal diseases. In the present study, 13 samples of EBER-positive gastric cancer with DNA viral loads of more than 2,000 copies per 100,000 cells were considered EBV-associated gastric cancers (EBVaGC). As exhibited in Table 2, there is a significant relationship between EBER gene positivity and age, and most people with EBVaGC are over 55 years old $(P=0.006)$. Also, the simultaneous infections of EBV and HP were detected in 17 of 35 EBER positive samples (48.6\%), 6 (17/1\%) case was in GC group and 11 (31/4\%) case was in the gastroduodenal diseases group. The absence of a significant association between dual infection by EBV and HP indicates the lack of synergistic effect of HP/EBV coinfection in the induction of gastric cancer $(P=0.903)$.

\section{Discussion}

Gastric cancer is recognized as a global health problem with higher than 1,000,000 new cases in 2018 and is the major reason for cancer death in some West Asian countries, including Turkmenistan, Kyrgyzstan, and Iran $(1,18,19)$. The fact that about $50 \%$ of gastric tumors are negative for HP and the presence of the EBV genome in about $10 \%$ of gastric cancers worldwide highlights the importance of studying EBVaGC $(13,20-22)$. Despite studies on the interaction of EBV and HP infection in GC, no definitive results have been obtained (23). North and Northwest are among the regions of Iran where the risk of gastric cancer is high (24). The present study aimed to assess the status of EBV infection by Real-Time PCR in 237 gastroduodenal samples, and also to determine the association between EBV and HP infection with gastric cancer and other gastroduodenal diseases in Babol, Northern Iran. Generally, by observing EBV DNA with more than 2000 copies per 100,000 cells in 13 GC samples (16\%), a high incidence of EBVaGC was reported in Babol.

Helicobacter pylori as the most major cause of gastric cancer, is responsible for more than $60 \%$ of GC cases and a different prevalence of this bacteria has been reported in populations studied $(22,23,25)$. There is a higher prevalence of infection by this pathogen in developing countries compared to developed countries (26). According to the results, the rate of HP infection was higher in subjects with DU (90.3\%) than that observed in subjects with GC (39.5\%), GU (35\%), and GA (22.4\%). In studies by Moral- Hernández et al, Saxena et al, and Teresa et al similar to our results, a low prevalence of HP infection was reported in GC specimens, namely, 40.6\%, 56.5\%, and 50\%, respectively $(22,23,27)$. Factors such as HP concealment within mucosal cells and lack of urease production in the lumen, the bias in obtaining patient information, a history of receiving antimicrobial therapy for HP, and the use of different diagnostic methods may be reasons for different frequencies of HP reported in populations $(22,23)$.

Epstein-Barr virus EBER is one of the transcripts produced in EBV infections, which can by inducing insulin-like growth factor-1 (IGF1) participate in epithelial cell growth and gastric malignancy. In situ hybridization of EBER (EBER-ISH), defined as the gold standard for EBV status identification in GC samples, and the prevalence of 5-17.9\% EBER-positive tumor tissue has been recorded in a systematic review of 34 studies using this method. PCR is another method that has been considered in histological examination of the virus due to its high sensitivity and possible loss of a portion of the EBV infection with the EBER-ISH $(13,28-30)$. Using PCR and according to our results, EBER detection in GU samples was higher than DU, GA, and GC samples (35\%, $21.9 \%, 19.6 \%$, and $16 \%$, respectively) and was significantly associated with pathology diagnosis. It was also higher than the frequency of EBV-positive GC cases reported in two previous studies in Iran in 2007 and 2014 (3\% and 6.66\% respectively) (24,31). In countries with a high risk of GC, like Iran and Japan, a low incidence of EBVaGC has been reported, However, our study with high frequency EBVaGC (16\%) was 
inconsistent with two previous studies in Iran (24). In addition, inconsistent with our evidence, in a 2020 study by Aversa et al, on a large population of gastric adenocarcinoma, a low prevalence of EBVaGC was reported (22 out of 1035 cases) among a high-incidence Chinese population (32). In studies of different populations to investigate the presence of the $\mathrm{EBV}$ in GC and gastrointestinal disease, the detection rate of the EBV genome is very different, and there is conflicting information about the association of this virus with the induction of gastrointestinal malignancies, although factors such as detection methods, populations size, geographical and environmental aspects can be the cause of these variations (22-25, 28, 33-35). For example, in Nogueira et al and Guo et al studies, consistent with many previous investigations (36), the higher prevalence of EBV among GC subjects was observed by PCR than EBER-ISH, which were $90.2 \%$ versus $11 \%$, and $53.7 \%$ versus $6.7 \%$, respectively.

In many previous studies, EBVaGC was significantly associated with the male gender, and subjects with gastric cancer were predominantly male. In our study, the lack of EBVaGC association with gender $(P=0.501)$ did not confirm that males are more probably to diagnosed with EBVaGC than women. Of course, factors such as lifestyle, different genetic backgrounds, or hormonal conditions between the genders can affect the incidence of the disease $(25,28,36)$. Contrary to our findings, a meta-analysis conducted in 2020 interestingly showed a higher incidence of EBVaGC in women (36). Age is another risk factor for EBV-related gastric carcinoma development, and according to our observations, there is a significant correlation between age with GC and GU, so that most patients with an average age of over 55 years have GC and $\mathrm{GU}(\mathrm{P}<0.001)$. Consistent with our results, several investigations have reported a high frequency of EBVaGC at older ages $(28,35)$, Furthermore, inconsistent with our findings some studies showed more frequency of this subtype of cancer at a younger age (32).

In the current study, the determination of EBV DNA quantity in cancer and gastroduodenal disease groups was performed by the Real-Time PCR method. According to the results, more copy numbers of EBV EBER-DNA with a mean of $2.14 \times 10^{-1}$ copies per cell were observed in the GC group than in the gastroduodenal disease with a mean of $1.39 \times 10^{-2}$ copies per cell. Also, none of the gastric specimens with normal histology were positive for EBV EBER-DNA. To our knowledge, this is the first study conducted in Iran that reported data on the prevalence and viral load of EBV DNA in gastric cancer and gastroduodenal diseases. The high EBV EBER DNA quantities in the cancer group may suggest the presence of EBV-related tumors and the possible role of EBV in the development of gastric cancer.

In various studies on the association of the EBV/HP coinfection with gastric pathogenesis, the main focus on gastric cancer and the inclusion of benign disorders as a control group is considered a major limitation (37). Some of these studies suggest the existence of a synergic effect between EBV and HP in the pathogenesis of gastric disorders and carcinogenesis $(22,23,38-40)$. Maintaining the inflammatory state and further damage to the gastric mucosa by increasing IL-17 expression is one of the results of synergy between the two pathogens $(22,25,33)$. In our study, the absence of a statistically significant difference between dual infections of both pathogens among cancerous and noncancerous groups did not indicate any interaction between EBV and HP in gastric cancer development $(P=0.903)$. Opposite to many studies, which showed that the frequency of coinfection was higher in gastric cancer samples than in other gastric disorders, in the present study, the highest frequency of double infection was observed in DU (70\%) in comparison with GC $(13 \%)(22,23,27,33)$. Of course, similar to our results in some studies, such as the study carried by Saxena et al, the prevalence of co-infections in peptic ulcer disease (62.2\%) was higher than gastric cancer (46.8\%) (23).

\section{Conclusion}

This study highlights EBV prevalence in gastric cancer and gastroduodenal diseases. Our investigation showed that EBV viral load was significantly higher in the gastric cancer group as compared to the gastroduodenal disease group. This virus was present in gastrointestinal malignancies with a high incidence of $16 \%$. It can be noted that the small sample size was one of the limitations of our study, which may be resolved in similar future investigations. Moreover, the 
etiological contribution of this virus to the development of gastric cancer and other gastroduodenal diseases needs to be further explored in prospective follow-up studies.

\section{Abbreviations}

EBV: Epstein-Barr Virus

EBER: EBV-encoded small RNA

GC: gastric cancer

HP: Helicobacter pylori

GA: gastritis

GU: gastric ulcer

DU: duodenal ulcer

FFPE: formalin-fixed paraffin-embedded

CM: congested mucosa

IQR: interquartile range

RUT: rapid urease test

BMl: body mass index

IGF1: insulin-like growth factor-1

ISH: In situ hybridization

\section{Declarations}

\section{Ethics approval and consent to participate}

This study was approved by the Ethical Committee of Babol University of Medical Sciences (Project code: 9503117), and for all subjects, written informed consent was obtained.

\section{Consent for publication}

Not applicable.

\section{Availability of data and materials}

The datasets used and/or analysed during the current study are available from the corresponding author on reasonable request.

\section{Competing interests}

The authors declare no financial or commercial compete of interest. 


\section{Funding}

This study was financially supported by a grant from Babol University of Medical Sciences (Project code: 9503117).

\section{Authors' contributions}

FS: developed the study concepts, experimental protocols and revised the manuscript draft.

AZ, MP, and YY: prepared the manuscript draft.

AYC and SSA: carried out experimental protocols.

MR and JSS: carried out sample collection.

All authors read and approved the final manuscript.

\section{Acknowledgments}

We would like to express our appreciation to the directors and staff of Pathology Department of Ayatollah Rouhani Hospital affiliated to Babol University of Medical Sciences for their collaboration in sample collection. This study was financially supported by a grant from Babol University of Medical Sciences (Project code: 9503117).

\section{References}

1. Bray F, Ferlay J, Soerjomataram I, Siegel RL, Torre LA, Jemal A. Global cancer statistics 2018: GLOBOCAN estimates of incidence and mortality worldwide for 36 cancers in 185 countries. CA: a cancer journal for clinicians. 2018;68(6):394-424.

2. Karimi P, Islami F, Anandasabapathy S, Freedman ND, Kamangar F. Gastric cancer: descriptive epidemiology, risk factors, screening, and prevention. Cancer Epidemiology and Prevention Biomarkers. 2014;23(5):700-13.

3. Graham DY. Helicobacter pylori infection in the pathogenesis of duodenal ulcer and gastric cancer: a model. Gastroenterology. 1997;113(6):1983-91.

4. Forman D, De Backer G, Elder J, Moller H, Damotta L, Roy P, et al. EPIDEMIOLOGY OF, AND RISK-FACTORS FOR, HELICOBACTER-PYLORI INFECTION AMONG 3194 ASYMPTOMATIC SUBJECTS IN 17 POPULATIONS. Gut. 1993;34(12):1672-6.

5. Correa P, Piazuelo M, Camargo M. Etiopathogenesis of gastric cancer. Scandinavian Journal of Surgery. 2006;95(4):218-24.

6. Gulley ML, Pulitzer DR, Eagan PA, Schneider BG. Epstein-Barr virus infection is an early event in gastric carcinogenesis and is independent of bcl-2 expression and p53 accumulation. Human pathology. 1996;27(1):20-7.

7. Young LS, Yap LF, Murray PG. Epstein-Barr virus: more than 50 years old and still providing surprises. Nature Reviews Cancer. 2016;16(12):789-802.

8. Crawford DH. Biology and disease associations of Epstein-Barr virus. Philosophical Transactions of the Royal Society of London Series B: Biological Sciences. 2001;356(1408):461-73.

9. Martínez-López JL, Torres J, Camorlinga-Ponce M, Mantilla A, Leal YA, Fuentes-Pananá EM. Evidence of EpsteinBarr virus association with gastric cancer and non-atrophic gastritis. Viruses. 2014;6(1):301-18.

10. Hohaus S, Santangelo R, Giachelia M, Vannata B, Massini G, Cuccaro A, et al. The viral load of Epstein-Barr virus (EBV) DNA in peripheral blood predicts for biological and clinical characteristics in Hodgkin lymphoma. Clinical Cancer Research. 2011;17(9):2885-92. 
11. Lin J-C, Wang W-Y, Chen KY, Wei Y-H, Liang W-M, Jan J-S, et al. Quantification of plasma Epstein-Barr virus DNA in patients with advanced nasopharyngeal carcinoma. New England Journal of Medicine. 2004;350(24):2461-70.

12. Grywalska E, Roliński J, Pasiarski M, Korona-Glowniak I, Maj M, Surdacka A, et al. High viral loads of Epstein-Barr virus DNA in peripheral blood of patients with chronic lymphocytic leukemia associated with unfavorable prognosis. PLoS One. 2015;10(10):e0140178.

13. Ryan JL, Morgan DR, Dominguez RL, Thorne LB, Elmore SH, Mino-Kenudson M, et al. High levels of Epstein-Barr virus DNA in latently infected gastric adenocarcinoma. Laboratory investigation. 2009;89(1):80-90.

14. Yahyapour Y, Sadeghi F, Alizadeh A, Rajabnia R, Siadati S. Detection of merkel cell polyomavirus and human papillomavirus in esophageal squamous cell carcinomas and non-cancerous esophageal samples in northern Iran. Pathology \& Oncology Research. 2016;22(4):667-72.

15. Yahyapour Y, Shamsi-Shahrabadi M, Mahmoudi M, Siadati S, Shahryar SS, Shokri-Shirvani J, et al. Evaluation of human papilloma virus infection in patients with esophageal squamous cell carcinoma from the Caspian Sea area, north of Iran. Asian Pacific Journal of Cancer Prevention. 2012;13(4):1261-6.

16. Ling PD, Vilchez RA, Keitel WA, Poston DG, Peng RS, White ZS, et al. Epstein-Barr virus DNA loads in adult human immunodeficiency virus type 1-infected patients receiving highly active antiretroviral therapy. Clinical infectious diseases. 2003;37(9):1244-9.

17. Sadeghi F, Salehi-Vaziri M, Ghodsi SM, Alizadeh A, Bokharaei-Salim F, Saroukalaei ST, et al. Prevalence of JC polyomavirus large $T$ antigen sequences among Iranian patients with central nervous system tumors. Archives of virology. 2015;160(1):61-8.

18. Eusebi LH, Telese A, Marasco G, Bazzoli F, Zagari RM. Gastric cancer prevention strategies: a global perspective. Journal of gastroenterology and hepatology. 2020;35(9):1495-502.

19. Thrift AP, El-Serag HB. Burden of gastric cancer. Clinical Gastroenterology and Hepatology. 2020;18(3):534-42.

20. Yanagi A, Nishikawa J, Shimokuri K, Shuto T, Takagi T, Takagi F, et al. Clinicopathologic Characteristics of EpsteinBarr Virus-Associated Gastric Cancer Over the Past Decade in Japan. Microorganisms. 2019;7(9):305.

21. Tsai CY, Liu YY, Liu KH, Hsu JT, Chen TC, Chiu CT, et al. Comprehensive profiling of virus microRNAs of Epstein-Barr virus-associated gastric carcinoma: highlighting the interactions of ebv-Bart9 and host tumor cells. Journal of gastroenterology and hepatology. 2017;32(1):82-91.

22. Del Moral-Hernández O, Castañón-Sánchez CA, Reyes-Navarrete S, Martínez-Carrillo DN, Betancourt-Linares R, Jiménez-Wences $\mathrm{H}$, et al. Multiple infections by EBV, HCMV and Helicobacter pylori are highly frequent in patients with chronic gastritis and gastric cancer from Southwest Mexico: An observational study. Medicine. 2019;98(3).

23. Saxena A, Nath Prasad K, Chand Ghoshal U, Krishnani N, Roshan Bhagat M, Husain N. Association of Helicobacter pylori and Epstein-Barr virus with gastric cancer and peptic ulcer disease. Scandinavian journal of gastroenterology. 2008;43(6):669-74.

24. Faghihloo E, Saremi MR, Mahabadi M, Akbari H, Saberfar E. Prevalence and Characteristics of Epstein barr Virusassociated Gastric Cancer in Iran. Archives of Iranian medicine. 2014;17(11):767-70.

25. Nogueira C, Mota M, Gradiz R, Cipriano MA, Caramelo F, Cruz H, et al. Prevalence and characteristics of EpsteinBarr virus-associated gastric carcinomas in Portugal. Infectious agents and cancer. 2017;12(1):1-8.

26. de Souza CRT, de Oliveira KS, Ferraz JJS, Leal MF, Calcagno DQ, Seabra AD, et al. Occurrence of Helicobacter pylori and Epstein-Barr virus infection in endoscopic and gastric cancer patients from Northern Brazil. BMC gastroenterology. 2014;14(1):1-9.

27. Teresa F, Serra N, Capra G, Mascarella C, Gagliardi C, Di Carlo P, et al. Helicobacter pylori and epstein-barr virus infection in gastric diseases: correlation with IL-10 and IL1RN polymorphism. Journal of oncology. 2019;2019. 
28. Guo C, Wei J, Scott RS, Chen Y, Chen Z, Zhao W, et al. Prevalence and characteristics of Epstein-Barr virus associated gastric carcinoma in Gansu Province, Northwest China with mRNA expression of glycoprotein BMRF2. Journal of medical virology. 2020;92(3):356-63.

29. de Souza CRT, Almeida MCA, Khayat AS, da Silva EL, Soares PC, Chaves LC, et al. Association between Helicobacter pylori, Epstein-Barr virus, human papillomavirus and gastric adenocarcinomas. World journal of gastroenterology. 2018;24(43):4928.

30. Bae J-M, Kim EH. Epstein-Barr virus and gastric cancer risk: a meta-analysis with meta-regression of case-control studies. Journal of Preventive Medicine and Public Health. 2016;49(2):97.

31. Abdirad A, Ghaderi-Sohi S, Shuyama K, Koriyama C, Nadimi-Barforoosh H, Emami S, et al. Epstein-Barr virus associated gastric carcinoma: a report from Iran in the last four decades. Diagnostic Pathology. 2007;2(1):1-9.

32. Aversa JG, Song M, Hu N, Goldstein AM, Hewitt SM, Gulley ML, et al. Low epstein-barr virus prevalence in cardia gastric cancer among a high-incidence Chinese population. Digestive Diseases and Sciences. 2021;66(4):1220-6.

33. Castaneda CA, Castillo M, Chavez I, Barreda F, Suarez N, Nieves J, et al. Prevalence of Helicobacter pylori infection, its virulent genotypes, and Epstein-Barr virus in Peruvian patients with chronic gastritis and gastric cancer. Journal of global oncology. 2019;5:1-9.

34. Zhou H, Tan S, Li H, Lin X. Expression and significance of EBV, ARID1A and PIK3CA in gastric carcinoma. Molecular medicine reports. 2019;19(3):2125-36.

35. Herrera-Goepfert R, Akiba S, Koriyama C, Ding S, Reyes E, Itoh T, et al. Epstein-Barr virus-associated gastric carcinoma: Evidence of age-dependence among a Mexican population. World journal of gastroenterology: WJG. 2005;11(39):6096.

36. Tavakoli A, Monavari SH, Solaymani Mohammadi F, Kiani SJ, Armat S, Farahmand M. Association between EpsteinBarr virus infection and gastric cancer: a systematic review and meta-analysis. BMC cancer. 2020;20:1-14.

37. Dávila-Collado R, Jarquín-Durán O, Dong LT, Espinoza JL. Epstein-Barr Virus and Helicobacter Pylori Co-Infection in Non-Malignant Gastroduodenal Disorders. Pathogens. 2020;9(2):104.

38. Lima VP, de Lima MAP, André AR, Ferreira MVP, Barros MAP, Rabenhorst SHB. H pylori (CagA) and Epstein-Barr virus infection in gastric carcinomas: correlation with p53 mutation and c-Myc, Bcl-2 and Bax expression. World journal of gastroenterology: WJG. 2008;14(6):884.

39. Ferrasi AC, Pinheiro NA, Rabenhorst SHB, Caballero OL, Rodrigues MAM, Carvalho F, et al. Helicobacter pylori and EBV in gastric carcinomas: methylation status and microsatellite instability. World Journal of Gastroenterology: WJG. 2010;16(3):312.

40. Minoura-Etoh J, Gotoh K, Sato R, Ogata M, Kaku N, Fujioka T, et al. Helicobacter pylori-associated oxidant monochloramine induces reactivation of Epstein-Barr virus (EBV) in gastric epithelial cells latently infected with EBV. Journal of medical microbiology. 2006;55(7):905-11.

\section{Tables}

Table 1. Statistical associations between histopathologic groups and demographic and clinical characteristics of patients 


\begin{tabular}{|c|c|c|c|c|c|c|c|c|}
\hline \multicolumn{2}{|l|}{ Variable } & GC & GU & DU & GA & CM & Total & P-value \\
\hline \multicolumn{2}{|c|}{ Number of Patients } & $81(34.1 \%)$ & $20(8.4 \%)$ & $32(13.5 \%)$ & $51(21.5 \%)$ & $53(22.4 \%)$ & 237 & - \\
\hline \multirow{2}{*}{$\begin{array}{l}\text { Age } \\
\text { Group }\end{array}$} & $\leq 55$ & $20(24.7 \%)$ & $7(35 \%)$ & $25(78.1 \%)$ & $39(76.5 \%)$ & $40(76.9 \%)$ & $131(55.5 \%)$ & \multirow[t]{2}{*}{$P<0.001$} \\
\hline & $>55$ & $61(75.3 \%)$ & $13(65 \%)$ & $7(21.9 \%)$ & $12(23.5 \%)$ & $12(23.1 \%)$ & $105(44.5 \%)$ & \\
\hline \multirow{2}{*}{ Gender } & Male & $57(70.4 \%)$ & $11(55 \%)$ & $15(46.9 \%)$ & $24(47.1 \%)$ & $23(43.4 \%)$ & $130(54.9 \%)$ & \multirow[t]{2}{*}{$P=0.013$} \\
\hline & Female & $24(29.6 \%)$ & $9(45 \%)$ & $17(53.1 \%)$ & $27(52.9 \%)$ & $30(56.6 \%)$ & $107(45.1 \%)$ & \\
\hline \multirow{2}{*}{$\begin{array}{l}\text { Smoking } \\
\text { status }\end{array}$} & Smoker & $8(10.8 \%)$ & $2(10 \%)$ & $3(9.7 \%)$ & $4(8.3 \%)$ & $12(24 \%)$ & $29(13 \%)$ & \multirow[t]{2}{*}{$P=0.133$} \\
\hline & $\begin{array}{l}\text { Non- } \\
\text { Smoker }\end{array}$ & $66(89.2 \%)$ & $18(90 \%)$ & $28(90.3 \%)$ & $44(91.7 \%)$ & $38(76 \%)$ & $194(87 \%)$ & \\
\hline \multirow{2}{*}{$\begin{array}{l}\text { Alcohol } \\
\text { Drinking }\end{array}$} & Yes & $5(6.9 \%)$ & $3(15 \%)$ & $2(6.5 \%)$ & $9(18.8 \%)$ & $4(8 \%)$ & $23(10.4 \%)$ & \multirow[t]{2}{*}{$P=0.215$} \\
\hline & No & $67(93.1 \%)$ & $17(85 \%)$ & $29(93.5 \%)$ & $39(81.3 \%)$ & $46(92 \%)$ & 198(89.6\%) & \\
\hline \multirow{2}{*}{$\begin{array}{l}\text { Family } \\
\text { History } \\
\text { Of GC }\end{array}$} & Yes & $16(21.9 \%)$ & $5(25 \%)$ & $4(13.3 \%)$ & $4(9.8 \%)$ & $5(10 \%)$ & $34(15.9 \%)$ & \multirow[t]{2}{*}{$P=0.213$} \\
\hline & No & $57(78.1 \%)$ & $15(75 \%)$ & $26(86.7 \%)$ & $37(90.2 \%)$ & $45(90 \%)$ & $180(84.1 \%)$ & \\
\hline \multirow{2}{*}{$\begin{array}{l}\text { History } \\
\text { of drug } \\
\text { use }\end{array}$} & Yes & $8(11 \%)$ & $2(10 \%)$ & $3(9.7 \%)$ & $4(8.3 \%)$ & $2(4 \%)$ & $19(8.6 \%)$ & \multirow[t]{2}{*}{$P=0.741$} \\
\hline & No & $65(89 \%)$ & $18(90 \%)$ & $28(90.3 \%)$ & $44(91.7 \%)$ & $48(96 \%)$ & $203(91.4 \%)$ & \\
\hline \multirow[b]{2}{*}{ BMI } & $\leq 24 / 99$ & $50(66.7 \%)$ & $4(22.2 \%)$ & $11(37.9 \%)$ & $19(43.2 \%)$ & $24(47.1 \%)$ & $108(49.8 \%)$ & \multirow[t]{2}{*}{$P=0.002$} \\
\hline & $>25$ & $25(33.3 \%)$ & $14(77.8 \%)$ & $18(62.1 \%)$ & $25(56.8 \%)$ & $27(52.9 \%)$ & $109(50.2 \%)$ & \\
\hline \multirow[b]{2}{*}{ H. pylori } & Positive & $30(39.5 \%)$ & $7(35 \%)$ & $28(90.3 \%)$ & $11(22.4 \%)$ & $0(0 \%)$ & $76(33.2 \%)$ & \multirow[b]{2}{*}{$P<0.001$} \\
\hline & Negative & $46(60.5 \%)$ & $13(65 \%)$ & $3(9.7 \%)$ & $38(77.6 \%)$ & $53(100 \%)$ & $153(66.8 \%)$ & \\
\hline \multirow[b]{2}{*}{ EBV } & Positive & $13(16 \%)$ & $7(35 \%)$ & $7(21.9 \%)$ & $10(19.6 \%)$ & $0(0 \%)$ & $37(15.6 \%)$ & \multirow[b]{2}{*}{$P=0.002$} \\
\hline & Negative & $68(84 \%)$ & $13(65 \%)$ & $25(78.1 \%)$ & $41(80.4 \%)$ & $53(100 \%)$ & $200(84.4 \%)$ & \\
\hline
\end{tabular}

Table 2. Demographic, clinical and virologic parameters of 37 EBER positive cases with GC and Gastro duodenal disease 


\begin{tabular}{|c|c|c|c|c|c|}
\hline \multicolumn{2}{|l|}{ Variable } & \multicolumn{2}{|l|}{ Patients Groups } & \multirow[b]{2}{*}{ Total } & \multirow[b]{2}{*}{ P-value } \\
\hline & & Gastric cancer & $\begin{array}{l}\text { Gastro duodenal } \\
\text { disease }\end{array}$ & & \\
\hline \multirow{3}{*}{\multicolumn{2}{|c|}{$\begin{array}{l}\text { Mean EBV DNA Load } \\
\text { (copies/cell) }\end{array}$}} & & & & $P<0.001$ \\
\hline & & $2.14 \times 10^{-1}$ & $1.39 \times 10^{-2}$ & $8.40 \times 10^{-2}$ & \\
\hline & & $\left(2.14 \times 10^{-2}-4.10 \times 10^{-1}\right)$ & $\left(1.11 \times 10^{-3}-2.35 \times 10^{-2}\right)$ & $\begin{array}{l}\left(1.11 \times 10^{-3}-\right. \\
\left.-4.10 \times 10^{-1}\right)\end{array}$ & \\
\hline \multirow{2}{*}{ Age Group } & $\leq 55$ & $2 / 37(5.4 \%)$ & 15/37 (40.5\%) & 17/37 (45.9\%) & \multirow[t]{2}{*}{$P=0.006$} \\
\hline & $>55$ & $11 / 37(29.7 \%)$ & $9 / 37(24.4 \%)$ & $20 / 37(54.1 \%)$ & \\
\hline \multirow[b]{2}{*}{ Gender } & Male & $8 / 37(21.6 \%)$ & $12 / 37(32.4 \%)$ & $20 / 37$ (54.1\%) & \multirow[t]{2}{*}{$P=0.501$} \\
\hline & Female & $5 / 37(13.5 \%)$ & 12/37 (32.4\%) & $17 / 37(45.9 \%)$ & \\
\hline \multirow[b]{2}{*}{ Smoking status } & Smoker & $2 / 35(5.7 \%)$ & $2 / 35(5.7 \%)$ & $4 / 35(11.4 \%)$ & \multirow[t]{2}{*}{$P=0.594$} \\
\hline & $\begin{array}{l}\text { Non- } \\
\text { Smoker }\end{array}$ & $10 / 35(28.6 \%)$ & $21 / 35(60 \%)$ & $31 / 35(88.6 \%)$ & \\
\hline \multirow{2}{*}{$\begin{array}{l}\text { Family History of } \\
\text { GC }\end{array}$} & Yes & $4 / 31(12.9 \%)$ & $3 / 31(9.7 \%)$ & $7 / 31(22.6 \%)$ & \multirow[t]{2}{*}{$P=0.384$} \\
\hline & No & $8 / 31(25.8 \%)$ & $16 / 31(51.6 \%)$ & $24 / 31(77.4 \%)$ & \\
\hline \multirow{2}{*}{ H. pylori } & Positive & $6 / 35(17.1 \%)$ & $11 / 35$ (31.4\%) & $17 / 35(48.6 \%)$ & \multirow{2}{*}{$P=0.903$} \\
\hline & Negative & $6 / 35(17.1 \%)$ & $12 / 35(34.3 \%)$ & $18 / 35(51.4 \%)$ & \\
\hline
\end{tabular}

\section{Figures}




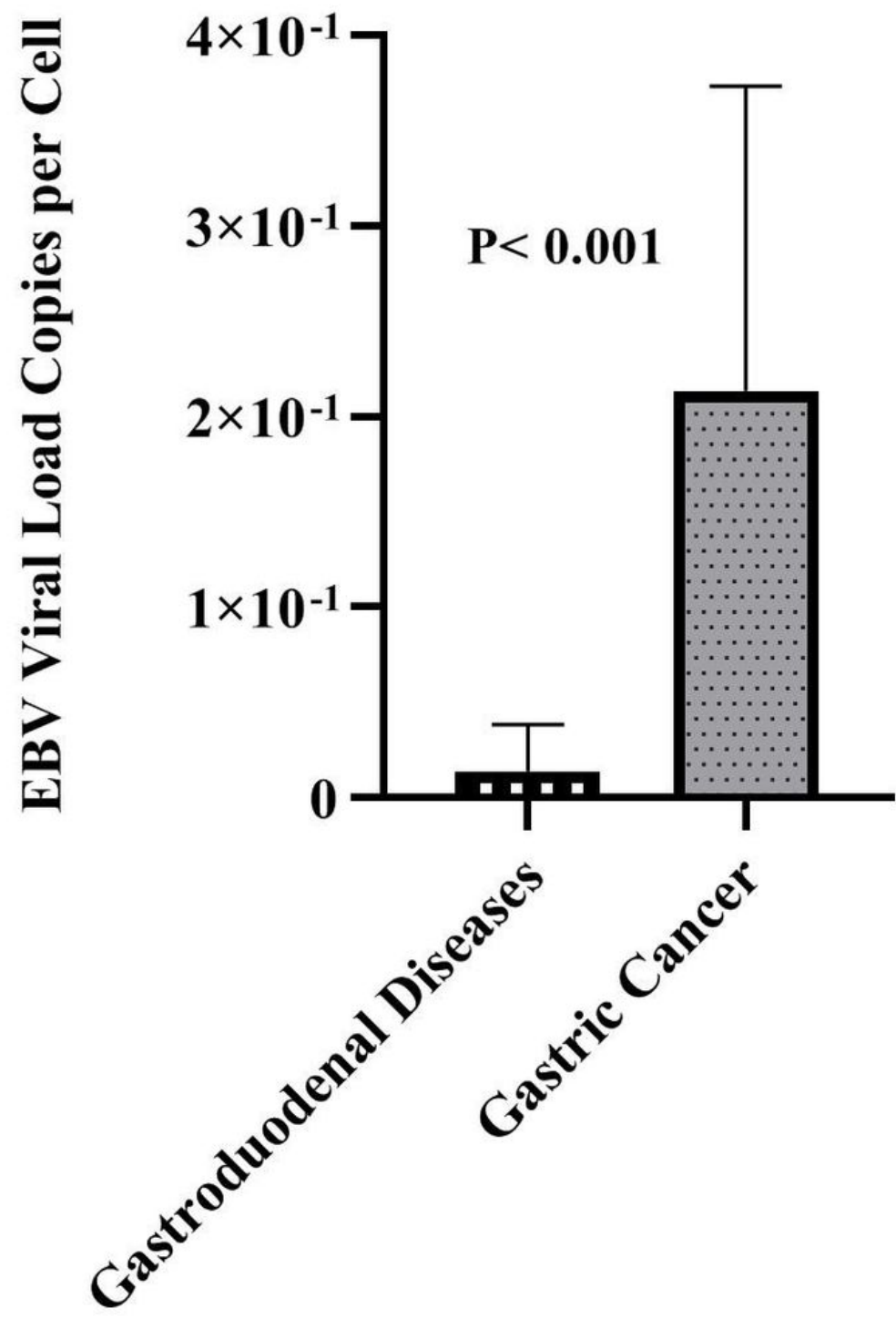

Figure 1

The mean EBV EBER DNA load in gastric cancer and gastroduodenal diseases groups. The P-value was determined by the Mann-Whitney U test. 